\title{
Phototherapy With LED as an Effective Treatment for Chemotherapy-Induced Oral Mucositis in Hamsters
}

\author{
Luana Campos $^{1,2}$, Claudia Carrara Cotomacio ${ }^{3}$, Victor Elias Arana-Chavez ${ }^{3}$, Alyne Simões ${ }^{3 *}$ \\ 'Department of post-graduation, School of Dentistry, University of Santo Amaro, São Paulo 04829-300, Brazil \\ ${ }^{2}$ Department of Oral Medicine, Brazilian Institute of Cancer Control, São Paulo 03102-002, Brazil \\ ${ }^{3}$ Laboratory of Oral Biology, Department of Biomaterials and Oral Biology, School of Dentistry, University of São Paulo, São \\ Paulo 05508-000, Brazil
}

\section{*Correspondence to \\ Luana Campos, \\ Department of post-graduation, School of Dentistry, University of Santo Amaro, São Paulo 04829 300, Brazil. \\ Tel: (+55 11) 21418615; Email: lucampos@prof.unisa.br \\ Published online October 3, 2020}

\section{Introduction}

The oral mucositis (OM) lesions are considered a frequent and painful side effect in oncologic patients submitted to high doses of chemotherapy. ${ }^{1,2}$ When severe, it can be related to cancer treatment delays, interruptions or discontinuation, as well as an increase in the frequency and cost of hospitalization. ${ }^{3}$ In addition, its moderate to severe grades could hamper the normal oral functions, such as feeding, speech, and swallowing, reducing the patients' quality of life. ${ }^{4}$

Different interventions have been evaluated with the aim of reducing OM, including systemic analgesics, coating agents, topic anesthetics/analgesics, mouth rinse, and oral cryotherapy. ${ }^{4}$ However, in recent years, an increased understanding of the pathophysiology and risk factors has been acquired, which has favored the development of new therapeutic strategies. ${ }^{4-9}$

The recent literature data have shown the effectiveness of low-level laser therapy (LLLT) in the prevention and treatment of $\mathrm{OM},{ }^{4-9}$ producing important analgesic, biomodulatory, and anti-inflammatory effects., ${ }^{4,6,9-16}$ This fact contributed to the International Society of Oral Oncology and the Multinational Association of Supportive Care in Cancer (MASCC/ISOO) raised the LLLT for a recommended therapy in their clinical practice guideline for OM management. ${ }^{4}$ However, besides LLLT, the use of light-emitting diode (LED) to treat lesions of OM has been studied with promising but still inconclusive results. ${ }^{6,17,18}$

Emitting monochromatic diffuse light in a therapeutic wavelength ranging from $635 \mathrm{~nm}$ (red) to $1300 \mathrm{~nm}$ (infrared), the LED is a semiconductor device that has been used as a new alternative to laser light and has demonstrated similar or even better effects on skin and mucosal wound healing, with the additional advantage of lower cost and a larger spot area to reach more tissue at once. ${ }^{6,818}$ Although fewer pieces of evidence have been gathered about the action mechanism of noncoherent light, LED therapy may promote a bio-stimulative effect upon irradiated cells. ${ }^{6,17,19-21}$ 
In the past few years, the published literature on the subject has shown positive, preventive and curative effects of LED therapy on chemotherapy and/or head and neck radiotherapy-induced OM. Furthermore, some authors have observed an immediate pain relief in pediatric patients who underwent a bone marrow transplant and were submitted to LED therapy. ${ }^{22}$ Recently, Freitas et al compared LLLT and LED therapeutic protocols to treat chemotherapy-induced $\mathrm{OM}$ in cancer patients and the authors concluded that the patients submitted to LED therapeutic protocol showed better results than those submitted to LLLT. ${ }^{8}$

Currently, few histological studies that examined the effect of LED on chemotherapy-induced OM (CIOM) are available. Thus, we aimed to evaluate, by clinical and histological analysis, whether the treatment with LED would yield effects comparable to those of the previous studies with LLLT by using an animal model of CIOM in hamsters.

\section{Material and Methods \\ Animals}

The experimental protocol presented was approved by the Ethical Committee for Animal Research of the USP (University of São Paulo), Brazil (Protocol 08.2016), and the principles of laboratory animal care (NIH 85-23, 1985) were applied for the present study.

Twenty male Golden Syrian hamsters were distributed into two groups: control (C), where animals received 5 -FU and $\mathrm{OM}$ induction $(\mathrm{n}=10)$; and LED (L), where animals received 5-FU, OM induction and treatment with LED therapy $(0.48 \mathrm{~J})(\mathrm{n}=10)$. A subgroup of each group was euthanized on days $5(n=5)$ and $10(n=5)$.

All hamsters weighed approximately $150 \mathrm{~g}$ and were 8 weeks old. They were maintained in ventilated plastic cages $\left(22^{\circ} \mathrm{C}\right)$ in a 12 -hour light/dark cycle and received food and water ad libitum.

\section{Experimental Protocol}

The experimental OM model was based on a previously published protocol. ${ }^{13,23}$ All the experiment lasted 10 consecutive days, and the OM was induced by 2 intraperitoneal injections of 5-fluorouracil (5-FU) (Sigma Chemical CO, St Louis, MO) on days 1 (100 mg/kg) and $3(65 \mathrm{mg} / \mathrm{kg})$, followed by scratches on both right and left cheek pouch mucosa on days 4 and 5, according to the protocol previously published by Campos et al. ${ }^{6}$ From day 4, all animals were anesthetized with Ketamine (Dopalen $^{\circledR}$, Vetbrands, Paulínia, São Paulo, Brazil) 116 $\mathrm{mg} / \mathrm{Kg}$ and Xylazine $13.8 \mathrm{mg} / \mathrm{Kg}$ (Anazedan ${ }^{\circledR}$, Vetbrands, Brazil) (Figure 1).

\section{LED Parameters}

The LED (Fisio LED - MMOptics ${ }^{\circledast}$ Ltda, São Carlos, São Paulo, Brazil) with a spot size of $1 \mathrm{~cm}^{2}$ and a wavelength of $635 \mathrm{~nm}$ was used at $120 \mathrm{~mW}$ of power, an irradiation

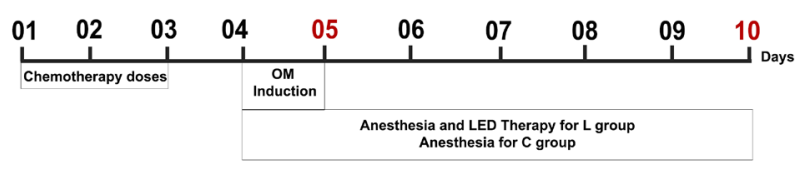

Figure 1. Study Design. Groups $C$ and $L$ received chemotherapy injections on days 1 and 3 and oral mucositis (OM) induction on days 4 and 5. Between days 4 and 10 only the L group received LED therapy. Red numbers (5 and 10) indicate the euthanasia days.

time of 4 seconds, and $0.48 \mathrm{~J}$ of energy. The irradiation was punctual (only a central point), in contact with and perpendicular to the oral mucosa (Figure 2).

\section{Clinical Evaluation}

The OM was evaluated by one trained examiner on days 4, 5, 7 and 10 through two specific assessment scales: Oral Mucositis Assessment Scale (OMAS) modified for hamsters according to Wilder-Smith et al ${ }^{24}$ and the criteria proposed by World Health Organization (WHO) $)^{13,24}$ (Figure 3). The body mass, food and drink not consumed of each animal were weighed daily.

\section{Morphological Analysis}

Ten samples were used for morphological analysis; for each group, 5 animals were euthanized on days 5 and 10 . Immediately after euthanasia, the samples of cheek pouch mucosa were removed and fixed in $4 \%$ formaldehyde and $0.1 \%$ glutaraldehyde (Polysciences, PA, USA) buffered in $0.1 \mathrm{M}$ sodium cacodylate at $\mathrm{pH}$ 7.2. After that, all the samples were dehydrated and embedded in historesin JB4 (Electron Microscopy Sciences, PA, USA). Three $3-\mu$ m-thick sections were obtained with a glass knife in a microtome (MICROM HM360, Germany) and stained with hematoxylin and acid fuchsin. The slides were examined in an Olympus BX60 light microscope equipped with an Olympus DP72 CCD camera.

\section{Statistical Analysis}

The results were subjected to statistical testing using ANOVA (analysis of variance) to compare quantitative

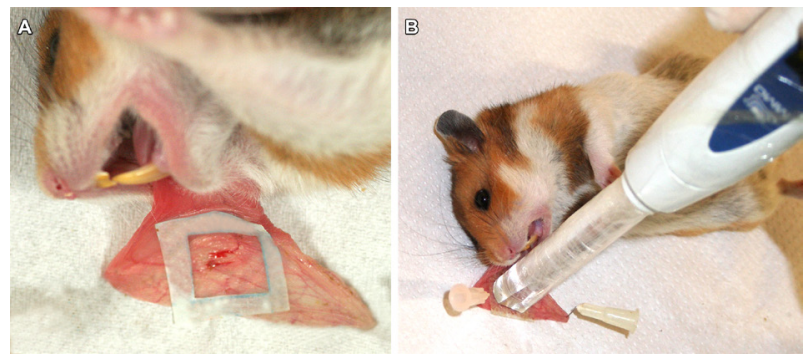

Figure 2. (A) cheek pouch mucosa everted, showing the final aspect of superficial scratching (oral mucositis induction) in the area bounded (1 $\mathrm{cm}^{2}$ ). (B) LED irradiation in contact with and perpendicular to the cheek pouch mucosa. 


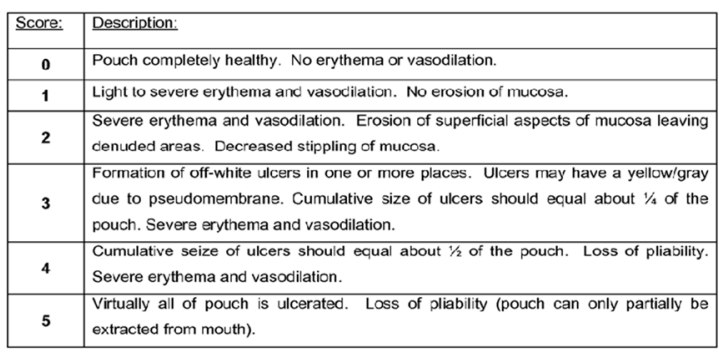

B

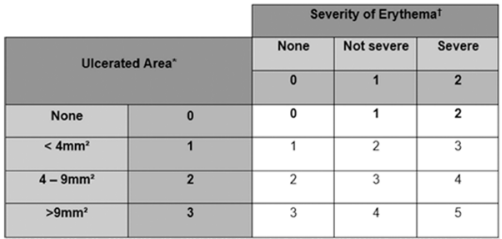

Figure 3. (A) World Health Organization (WHO) classification for oral mucositis; (B) Oral Mucositis Assessment Scale (OMAS) for oral mucositis.

variables and the Mann-Whitney U and Friedman tests to compare qualitative variables, with a power value of $90 \%$. The significance level was set at $5 \%$.

\section{Results}

\section{General Clinical Evaluation}

Both groups presented similar signs related to chemotherapy treatment, such as decrease of appetite, diarrhea, prostration and cachexia, with consequent weight loss.

Considering the food and water intake as well as the body mass loss, the groups $\mathrm{C}$ and $\mathrm{L}$ showed no statistical difference when compared to each other. The food intake was $28 \%$ higher in the $\mathrm{C}$ group, however the weight loss in the $\mathrm{C}$ group was $27 \%$ higher than the L group (Table 1).

\section{Clinical Evaluation of Oral Mucositis}

According to the WHO scale, on day 4, both groups showed grade 4 of OM. On day 5 , the L group maintained the same grade while the $C$ group ranged between 4 and 5 , with the median and mean scores near to 4 . On day 7 , the L group presented a significant decrease in the severity of lesions, showing grades between 1 and 3 and the mean and median values near to 2 , in comparison to the $\mathrm{C}$ group which showed grades between 3 and 5, with the mean and median scores near to $4(P<0.05)$. The L group showed only one animal with grade 4 on day 10 , while all the others presented grade 0 (mean near to 1 and median equal to zero). In contrast, the $\mathrm{C}$ group maintained the

Table 1. Body Mass Loss, Food and Water Intake of the C and L Groups on the Last Day of the Experiment (ANOVA)

\begin{tabular}{lccc}
\hline Group & Body Mass & Food Intake & Water Consumption \\
\hline $\mathrm{C}$ & $-26( \pm 2)^{\mathrm{a}}$ & $54( \pm 23)^{\mathrm{b}}$ & $89( \pm 17)^{\mathrm{c}}$ \\
$\mathrm{L}$ & $-19( \pm 2)^{\mathrm{a}}$ & $42( \pm 5)^{\mathrm{b}}$ & $95( \pm 9)^{\mathrm{c}}$ \\
\hline Different letters mean statistically significant differences $(P<0.05)$.
\end{tabular}

highest degrees, showing grades between 1 and 5, with the mean and median scores near to 2 (Figure 4A).

In the OMAS scale, both groups showed grade 3 on day 4 , with only one animal from the $\mathrm{C}$ group presenting grade 4. On day 5 , the group $\mathrm{L}$ presented grades ranging from 2 to 4 , with the median and mean scores near to 4 , while the C group maintained grade 4 . On Day 7 , the OM severity in the L group started to decrease and was between grades 3 and 1 , with the median and mean scores near to 2 . On the other hand, the $\mathrm{C}$ group showed OM grades between 3 and 5 and the mean and median scores near to 4, with only one animal showing grade 5 . On day 10 , the grades of OM decreased in both groups: the animals from the L group presented grade 0 , with one exception, showing grade 4 . Regarding the $\mathrm{C}$ group, the grades ranged from 1 to 3 , with one animal showing grade 5 (Figure 4B).

Both classifications presented similar results to the $\mathrm{L}$ and $\mathrm{C}$ groups on the follow-up. On days 4 and 5, were assessed severe grades of OM in both groups, however, on day 7 the scores of $70 \%$ of animals from the L group decreased and 30\% in the $\mathrm{C}$ group increased. Finally, on day 10 , there was complete healing for $90 \%$ of animals in the $\mathrm{L}$ group, while no animal from group $\mathrm{C}$ got the same result. For the WHO scale, the differences between the groups on each day started on day $7(P=0.002)$ and continued until day $10(P=0.002)$. For the OMAS scale, the differences also started on day $7(P=0.006)$ and continued until day $10(P=0.002)$ (Figure 4$)$.

The evaluation of the OM degree in each group over the days also revealed important differences. For the WHO scale, the L group showed differences when the OM grades were compared between days 7 and 10, as well as days 4 and $5(P<0.05)$. On the other hand, for group $C$, there were differences only when day 10 was compared with days 5 and $7(P<0.05)$. For the OMAS scale, the $\mathrm{L}$ group showed difference when day 10 was compared with days 4 and $5(P<0.05)$, and for the $C$ group, the difference was also related to day 10 , when compared with days 5 and $7(P<0.05)$.

\section{Histological Aspects}

On day 5, the animals from group $\mathrm{C}$ showed the mucosa with a disruption in the epithelium at the ulcer area, allowing the exposition of the subjacent connective tissue. Considering the lamina propria, a moderate inflammatory infiltrate was present, interspersed between the dense connective tissue with some dilated blood vessels (Figure 5A). On day 10, the ulcer was no longer identified. The lamina propria showed few inflammatory cells infiltrated into the connective tissue with collagen fibers (Figure 5B). The samples from group L on day 5 presented evident epithelium disruption, as observed for group C. The subjacent connective tissue, however, exhibited less inflammatory infiltrate as well as few blood vessels close to the ulcer region (Figure 4C). On day 10 , the epithelium was continuous, exhibiting a thin 
A

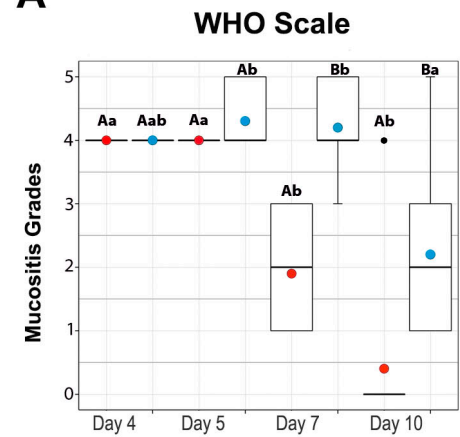

B

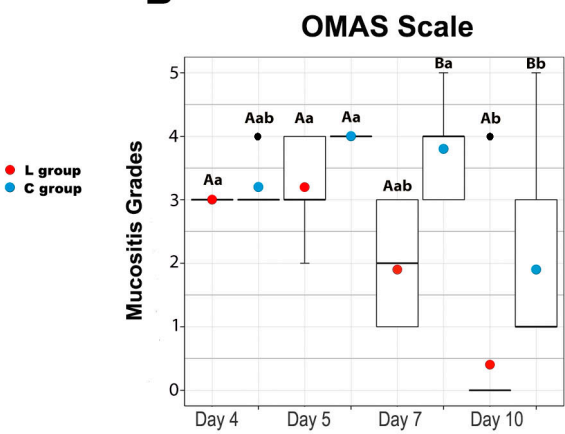

Figure 4. Oral Mucositis From Day 4 to 10. (A) WHO scale and grade description; (B) OMAS scale and scale description. Different uppercase letters: statistical differences between both groups on each day $(P<0.05$, Mann-Whitney test); Different lowercase letters: statistical difference in each group among the followup $(P<0.05$, Friedman test). Colorful circles, mean; bold line, median; dark dot, maximum and minimum single value.

corneous outer layer, whereas the underlying connective tissue appeared with few inflammatory cells between the collagen fibers (Figure 5D).

\section{Discussion}

The present study showed that LED therapy reduced the OM severity, promoting faster wound healing of the CIOM model. The experimental OM model employed in this

$$
\text { A }
$$
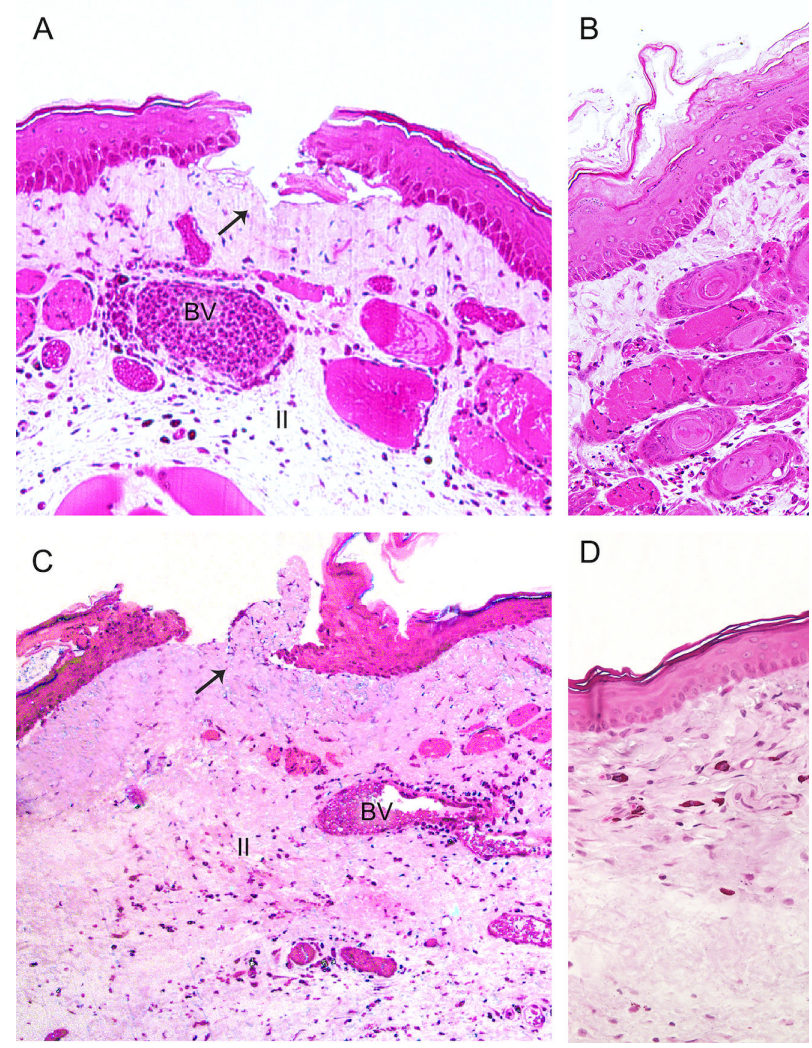

D

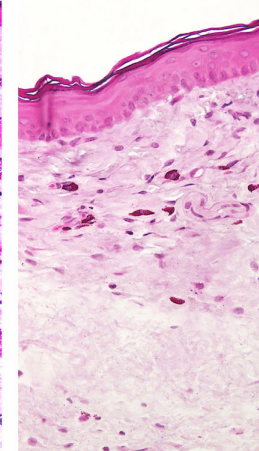

Figure 5. Light Micrographs of the Cheek Pouch Mucosa of Animals From the Different Experimental Groups. (A) C group on day 5: presence of ulcer (arrow), inflammatory infiltrate $\left(^{*}\right)$ and blood vessels (BV); (B) C group on day 10: inflammatory infiltrate $(*)$; (C) L group on day 5: ulcer (arrow), inflammatory infiltrate ${ }^{*}$ ) and blood vessels (BV); (D) L group on day 10 : blood vessel (BV). study yielded the general clinical signs shown in published studies. ${ }^{13,25}$ Both groups were systemically affected by chemotherapy, showing considerable body mass loss as well as decreased food and water consumption. Indeed, the 5-FU affects not only the oral mucosa, but also the entire gastrointestinal tract, may resulting in a reduction of nutrients and water absorption, contributing to the weight loss of the animals. ${ }^{25,26}$

Regarding the histological aspects, the treatment with LED was also able to maintain less severe inflammatory infiltrate, organized collagen fibers and epithelial cells. The anti-inflammatory effect of LED was assessed in an experimental model of collagenase-induced tendinitis in rats. The authors showed a significant improvement in the quality of tissue repair and a decrease in inflammatory cytokines. ${ }^{27}$ Sacono et al observed a highly cellularized collagen-rich area in connective tissue, suggestive of healing on animals treated with LED therapy ${ }^{15}$

Concerning the development of $\mathrm{OM}$ along the experimental period in this present study, the L group showed less severe degrees of lesions on day 5 and complete tissue repair by the end of the experiment, while the $\mathrm{C}$ group maintained severe $\mathrm{OM}$ degrees throughout the experiment. Previous studies that assessed the effect of LED therapy on the prevention and treatment of chemotherapy-induced OM in hamsters also concluded that the LED therapy was effective in reducing the severity of $\mathrm{OM}$, although the oral lesions were not completely prevented..$^{15}$

Clinical studies have also provided promising results of LED therapy. ${ }^{17,18,28}$ Corti et al evaluated 12 patients who were affected by hematological tumors and developed OM after high-doses of chemotherapy and were treated with LED. The study showed that LED treatment was safe and capable of reducing the duration of oral lesions. ${ }^{29}$ In a case report, some authors also evaluated the efficacy of LED therapy in preventing OM in a Hodgkin's patient treated with the doxorubicin, bleomycin, vinblastine, and dacarbazine chemotherapy regimen and they concluded that LED was an effective method for preventing this oral 
complication..$^{18}$

In a prospective study including 40 patients, the authors compared the effect of LED and LLLT on the treatment of chemotherapy-induced OM and showed better healing of $\mathrm{OM}$ in patients treated with LED than those receiving LLLT, although the authors concluded that both therapies were effective. ${ }^{8}$ Similarly, Freire et al, using a hamster model, compared the preventive and therapeutic effects of LED and LLLT therapies and concluded that both treatments were effective in diminishing OM severity. ${ }^{30}$

Chemotherapy-induced OM has numerous consequences. Concerning patients, it may cause severe pain and dysphagia that can lead to anorexia, weight loss and weakness. ${ }^{31}$ In light of the above, the therapy designed to prevent or accelerate its resolution should result in a significant benefit to the patient, improving the prognosis of the cancer treatment as well as contributing to healthcare cost savings. ${ }^{32}$

Although the MASCC/ISOO clinical practice guideline (2014) recommends LLLT to prevent OM, there is no supportive evidence that LED therapy could be also a good alternative. In that sense, the present results support the use of LED therapy as an alternative to LLLT, taking advantage of lower cost and a bigger spot area.

\section{Conclusion}

According to the protocol used in this study, LED therapy was a promising option for the treatment of CIOM.

\section{Ethical Considerations}

The study was approved by the Ethical Committee for Animal Research of the University of São Paulo, Brazil (Protocol 08.2016).

\section{Conflict of Interests}

The authors declare no conflict of interest.

\section{Acknowledgments}

This study was supported by grants from the FAPESP State of São Paulo Research Foundation (2011/14013-1) and CAPES (6257-12-7).

\section{References}

1. Bjordal JM, Bensadoun RJ, Tunèr J, Frigo L, Gjerde K, Lopes-Martins RA. A systematic review with meta-analysis of the effect of low-level laser therapy (LLLT) in cancer therapy-induced oral mucositis. Support Care Cancer. 2011;19(8):1069-77. doi: 10.1007/s00520-011-1202-0.

2. Scully C, Epstein J, Sonis S. Oral mucositis: a challenging complication of radiotherapy, chemotherapy, and radiochemotherapy: part 1, pathogenesis and prophylaxis of mucositis. Head Neck. 2003;25(12):1057-70. doi: 10.1002/hed.10318.

3. Murphy CK, Fey EG, Watkins BA, Wong V, Rothstein D, Sonis ST. Efficacy of superoxide dismutase mimetic M40403 in attenuating radiation-induced oral mucositis in hamsters. Clin Cancer Res. 2008;14(13):4292-7. doi:
10.1158/1078-0432.CCR-07-4669.

4. Lalla RV, Bowen J, Barasch A, Elting L, Epstein J, Keefe $\mathrm{DM}$, et al. MASCC/ISOO clinical practice guidelines for the management of mucositis secondary to cancer therapy. Cancer. 2014;120(10):1453-61. doi: 10.1002/cncr.28592.

5. Campos L, Simões A, Sá PH, Eduardo Cde P. Improvement in quality of life of an oncological patient by laser phototherapy. Photomed Laser Surg. 2009;27(2):371-4. doi: 10.1089/pho.2008.2300.

6. Campos L, Cruz ÉP, Pereira FS, Arana-Chavez VE, Simões A. Comparative study among three different phototherapy protocols to treat chemotherapy-induced oral mucositis in hamsters. J Biophotonics. 2016;9(11-12):1236-45. doi: 10.1002/jbio.201600014.

7. Cotomacio CC, Campos L, Nesadal de Souza D, Arana-Chavez VE, Simões A. Dosimetric study of photobiomodulation therapy in 5-FU-induced oral mucositis in hamsters. J Biomed Opt. 2017;22(1):18003. doi: 10.1117/1.JBO.22.1.018003.

8. Freitas $\mathrm{AC}$, Campos L, Brandão $\mathrm{TB}$, Cristófaro $\mathrm{M}$, Eduardo Fde P, Luiz AC, et al. Chemotherapy-induced oral mucositis: effect of LED and laser phototherapy treatment protocols. Photomed Laser Surg. 2014;32(2):81-7. doi: 10.1089/pho.2013.3576.

9. Simões A, Eduardo FP, Luiz AC, Campos L, Sá PH, Cristófaro $\mathrm{M}$, et al. Laser phototherapy as topical prophylaxis against head and neck cancer radiotherapyinduced oral mucositis: comparison between low and high/ low power lasers. Lasers Surg Med. 2009;41(4):264-70. doi: 10.1002/lsm.20758.

10. Anschau F, Webster J, Capra MEZ, de Azeredo da Silva ALF, Stein AT. Efficacy of low-level laser for treatment of cancer oral mucositis: a systematic review and metaanalysis. Lasers Med Sci. 2019;34(6):1053-62. doi: 10.1007/ s10103-019-02722-7.

11. Antunes HS, Schluckebier LF, Herchenhorn D, Small IA, Araújo CMM, Viégas CMP, et al. Cost-effectiveness of low-level laser therapy (LLLT) in head and neck cancer patients receiving concurrent chemoradiation. Oral Oncol. 2016;52:85-90. doi: 10.1016/j.oraloncology.2015.10.022.

12. Bensadoun RJ, Nair RG. Low-level laser therapy in the management of mucositis and dermatitis induced by cancer therapy. Photomed Laser Surg. 2015;33(10):487-91. doi: 10.1089/pho.2015.4022.

13. França CM, França CM, Núñez SC, Prates RA, Noborikawa E, Faria MR, et al. Low-intensity red laser on the prevention and treatment of induced-oral mucositis in hamsters. J Photochem Photobiol B. 2009;94(1):25-31. doi: 10.1016/j. jphotobiol.2008.09.006.

14. Marín-Conde F, Castellanos-Cosano L, Pachón-Ibañez J, Serrera-Figallo MA, Gutiérrez-Pérez JL, Torres-Lagares D. Photobiomodulation with low-level laser therapy reduces oral mucositis caused by head and neck radiochemotherapy: prospective randomized controlled trial. Int J Oral Maxillofac Surg. 2019;48(7):917-23. doi: 10.1016/j. ijom.2018.12.006.

15. Sacono NT, Costa CAS, Bagnato VS, Abreu-e-Lima FCB. Light-emitting diode therapy in chemotherapy-induced mucositis. Lasers Surg Med. 2008;40(9):625-33. doi: 10.1002/lsm.20677. 
16. Zecha JA, Raber-Durlacher JE, Nair RG, Epstein JB, Elad S, Hamblin MR, et al. Low-level laser therapy/ photobiomodulation in the management of side effects of chemoradiation therapy in head and neck cancer: part 2: proposed applications and treatment protocols. Support Care Cancer. 2016;24(6):2793-805. doi: 10.1007/s00520016-3153-y.

17. Freitas AC, Campos L, Brandão TB, Cristófaro $M$, Eduardo Fde P, Luiz AC, et al. Chemotherapy-induced oral mucositis: effect of LED and laser phototherapy treatment protocols. Photomed Laser Surg. 2014;32(2):81-7. doi: 10.1089/pho.2013.3576.

18. Lang-Bicudo L, Eduardo Fde P, Eduardo Cde P, Zezell DM. LED phototherapy to prevent mucositis: a case report. Photomed Laser Surg. 2008;26(6):609-13. doi: 10.1089/ pho.2007.2228.

19. Adamskaya N, Dungel P, Mittermayr R, Hartinger J, Feichtinger G, Wassermann K, et al. Light therapy by blue LED improves wound healing in an excision model in rats. Injury. 2011;42(9):917-21. doi: 10.1016/j. injury.2010.03.023.

20. Chaves ME, Araújo AR, Piancastelli AC, Pinotti M. Effects of low-power light therapy on wound healing: LASER $\mathrm{x}$ LED. An Bras Dermatol. 2014;89(4):616-23. doi: 10.1590/ abd1806-4841.20142519.

21. Corazza AV, Jorge J, Kurachi C, Bagnato VS. Photobiomodulation on the angiogenesis of skin wounds in rats using different light sources. Photomed Laser Surg. 2007;25(2):102-6. doi: 10.1089/pho.2006.2011.

22. Whelan HT, Connelly JF, Hodgson BD, Barbeau L, Post AC, Bullard G, et al. NASA light-emitting diodes for the prevention of oral mucositis in pediatric bone marrow transplant patients. J Clin Laser Med Surg. 2002;20(6):31924. doi: 10.1089/104454702320901107.

23. Sonis ST, Tracey C, Shklar G, Jenson J, Florine D. An animal model for mucositis induced by cancer chemotherapy. Oral Surg Oral Med Oral Pathol. 1990;69(4):437-43. doi: 10.1016/0030-4220(90)90376-4.

24. Wilder-Smith P, Hammer-Wilson MJ, Zhang J, Wang Q, Osann K, Chen Z, et al. In vivo imaging of oral mucositis in an animal model using optical coherence tomography and optical Doppler tomography. Clin Cancer Res. 2007;13(8):2449-54. doi: 10.1158/1078-0432.CCR-062234.
25. Cruz Éde P, Campos L, Pereira Fda S, Magliano GC, Benites BM, Arana-Chavez VE, et al. Clinical, biochemical and histological study of the effect of antimicrobial photodynamic therapy on oral mucositis induced by 5-fluorouracil in hamsters. Photodiagnosis Photodyn Ther. 2015;12(2):298-309. doi: 10.1016/j.pdpdt.2014.12.007.

26. Stringer AM, Gibson RJ, Logan RM, Bowen JM, Yeoh ASJ, Hamilton J, et al. Gastrointestinal microflora and mucins may play a critical role in the development of 5-Fluorouracil-induced gastrointestinal mucositis. Exp Biol Med (Maywood). 2009;234(4):430-41. doi: 10.3181/0810RM-301.

27. Xavier M, David DR, de Souza RA, Arrieiro AN, Miranda H, Santana ET, et al. Anti-inflammatory effects of low-level light emitting diode therapy on Achilles tendinitis in rats. Lasers Surg Med. 2010;42(6):553-8. doi: 10.1002/lsm. 20896.

28. Tenis CA, Martins MD, Gonçalves MLL, Silva DFT, Cunha Filho JJD, Martins MAT, et al. Efficacy of diode-emitting diode (LED) photobiomodulation in pain management, facial edema, trismus, and quality of life after extraction of retained lower third molars: A randomized, double-blind, placebo-controlled clinical trial. Medicine (Baltimore). 2018;97(37):e12264. doi: 10.1097/MD.0000000000012264.

29. Corti L, Chiarion-Sileni V, Aversa S, Ponzoni A, D’Arcais R, Pagnutti S, et al. Treatment of chemotherapy-induced oral mucositis with light-emitting diode. Photomed Laser Surg. 2006;24(2):207-13. doi: 10.1089/pho.2006.24.207.

30. Freire Mdo R, Freitas R, Colombo F, Valença A, Marques AM, Sarmento VA. LED and laser photobiomodulation in the prevention and treatment of oral mucositis: experimental study in hamsters. Clin Oral Investig. 2014;18(3):1005-13. doi: 10.1007/s00784-013-1058-4.

31. Lalla RV, Ashbury FD. The MASCC/ISOO mucositis guidelines: dissemination and clinical impact. Support Care Cancer. 2013;21(11):3161-3. doi: 10.1007/s00520013-1924-2.

32. Bezinelli LM, Eduardo FP, Neves VD, Correa L, Lopes RM, Michel-Crosato E, et al. Quality of life related to oral mucositis of patients undergoing haematopoietic stem cell transplantation and receiving specialised oral care with low-level laser therapy: a prospective observational study. Eur J Cancer Care (Engl). 2016;25(4):668-74. doi: 10.1111/ ecc. 12344 . 